Article

\title{
Risks and Benefits of Increased Nut Consumption: Cardiovascular Health Benefits Outweigh the Burden of Carcinogenic Effects Attributed to Aflatoxin $B_{1}$ Exposure
}

\author{
Hanna Eneroth ${ }^{1, *}$, Stina Wallin ${ }^{1}$, Karin Leander ${ }^{2}$, Johan Nilsson Sommar ${ }^{3}$ and \\ Agneta Åkesson 2 \\ 1 National Food Agency, Box 622, 75126 Uppsala, Sweden; stina.wallin@slv.se \\ 2 Institute of Environmental Medicine (IMM), Karolinska Institutet, Box 210, 17177 Stockholm, Sweden; \\ karin.leander@ki.se (K.L.), agneta.akesson@ki.se (A.Å.) \\ 3 Department of Public Health and Clinical Medicine, Umeå University, 90187 Umeå, Sweden; \\ johan.sommar@umu.se \\ * Correspondence: hanna.eneroth@slv.se; Tel.: +46-18-175-579
}

Received: 31 October 2017; Accepted: 4 December 2017; Published: 13 December 2017

\begin{abstract}
Nuts are rich in nutrients and mounting evidence shows that consumption reduces cardiovascular disease (CVD) incidence. Nuts may also be a major source of aflatoxin $\mathrm{B}_{1}$, a potent liver carcinogen and the risk/benefit balance is unknown. Based on national statistics and data from the PREDIMED intervention trial, we estimated the potential CVD-reduction if Swedes aged 55-79 consumed $30 \mathrm{~g}$ nuts/day, instead of the current national average of five grams per day. We also assessed the reduction in disability-adjusted life years (DALYs) due to myocardial infarction (MI) and stroke. We estimated the aflatoxin $B_{1}$ exposure from nuts and calculated the margin of exposure. The approximation that one nanogram aflatoxin $B_{1} / \mathrm{kg}$ body weight/day results in one additional liver cancer case/10 million person-years was used to estimate the number of liver cancer cases. The increased nut consumption scenario prevented more than 7000 CVDs in 2013 (306/100,000 person-years) and contributed to about 55,000 saved DALYs for stroke and 22,000 for MI. The concomitant increase in aflatoxin $B_{1}$ exposure caused an estimated zero to three additional cases of liver cancer, corresponding to 159 DALYs spent, emphasizing the associated risks. Increased nut consumption, as part of a varied healthy diet, is warranted even when aflatoxin $B_{1}$ exposure is taken into account. However, efforts to reduce aflatoxin exposure from food are essential.
\end{abstract}

Keywords: nuts; healthy diet; risk-and benefit assessment; cardiovascular disease; myocardial infarction; stroke; aflatoxin; liver cancer; disability-adjusted life years

\section{Introduction}

Evidence of the health benefits of nut consumption is increasing, with recent systematic reviews supporting the link between nut consumption and lower risk of coronary heart disease [1-3], cardiovascular disease (CVD) [1,4], and all-cause mortality [1,2,5]. Additional support for a causal relationship with CVD is provided by randomized clinical trials (RCTs) on the effects of nut consumption on blood lipid levels [6] and by the five-year PREDIMED intervention study performed in Spain among subjects at high CVD risk [7]. In the latter, a group consuming $30 \mathrm{~g}$ mixed nuts daily, in addition to their Mediterranean diet, had 28\% lower risk of CVD compared with controls advised to adhere to a reduced-fat diet [7].

Although nuts are rich in polyunsaturated fatty acids (PUFA, mainly $n-6$ ), dietary fiber and micronutrients such as vitamin E, magnesium, and selenium, they may also contain high levels of one 
of the most potent carcinogenic substances, the mycotoxin aflatoxin $B_{1}$ [8]. Aflatoxins are produced by molds and may be present in a range of foods, including nuts [9]. Both animal and epidemiological studies demonstrate associations between aflatoxin exposure and liver cancer [10], the second most common cause of death from cancer worldwide and a disease with a poor prognosis [11]. It has been estimated that $5-28 \%$ of the annual cases of hepatocellular carcinoma worldwide could be attributed to aflatoxin exposure [12], with the highest risk in regions with high aflatoxin exposure and high prevalence of chronic hepatitis B infection [10]. In European and other developed countries, cancer risk estimates are in the range $<0.01-0.10$ aflatoxin-induced cancers per 100,000 person-years, with wheat being the major contributing food commodity [13]. Nevertheless, because of its genotoxic carcinogenic properties no level of aflatoxin $B_{1}$ exposure is considered safe, complicating any dietary advice or guidelines on nut consumption. To the best of our knowledge, the burden of liver cancer in relation to the CVD benefits of increased nut consumption has not been estimated previously.

The aim of the present study was to estimate the benefits and risks of increasing nut consumption to $30 \mathrm{~g} /$ day, following a proposed approach [14]. The calculations were based on the Swedish population, which has on average low (five grams per day) national nut consumption [15], a similar incidence of major CVDs as the European Union (EU) average [16], and a low incidence of liver cancer. We estimated the potential numbers of CVD cases avoided and the liver cancer cases attributable to the increased nut consumption. The absolute health impact was estimated through calculation of the burden of disability and death, expressed as disability-adjusted life years (DALYs).

\section{Materials and Methods}

\subsection{Setting}

The Swedish population in 2013 (9.6 million inhabitants [17]) had an intermediate burden of CVD compared with other European countries, corresponding of 60 DALYs/1000 individuals [18]. Although CVD prevalence in Western Europe is low by global standards, CVD is the most common cause of death and disability [19]. The incidence of liver cancer in Sweden is low: 3.7/100,000 person-years for women and 8.7/100,000 person-years for men [20]. Nut consumption, based on a nation-wide dietary survey, is on average $5 \mathrm{~g} /$ day for women and men (women, $n=1005$, mean $5 \mathrm{~g}$, standard deviation $12 \mathrm{~g}$; men, $n=792$, mean $4 \mathrm{~g}$ standard deviation, $13 \mathrm{~g} /$ day) [15].

\subsection{Change in Nutrient Intake}

To estimate the changes in nutrient intake brought about by increased consumption of nuts in the population, we used a scenario with iso-caloric replacement of part of the average diet of adults in the nation-wide dietary survey [15]. Substitution of nuts for "average intake" was chosen because it is difficult to assume how increased nut intake would change the diet. The assumed consumption of $30 \mathrm{~g} /$ day of the PREDIMED mixture of nuts ( $15 \mathrm{~g}$ walnuts, $7.5 \mathrm{~g}$ hazelnuts and $7.5 \mathrm{~g}$ almonds [7]), corresponded to $10 \%(817 \mathrm{~kJ})$ of the total energy intake reported.

\subsection{Estimating Benefit: Nut Consumption and Cardiovascular Disease}

To estimate the CVD benefits in this study, we applied a scenario using the observed effects for the primary and secondary endpoints in the nut intervention in PREDIMED (30 g/day) on CVD incidence in the population. The primary endpoint was composite CVD, defined as fatal and non-fatal MI and stroke and death from heart failure, cardiac arrest, cardiomyopathy, pulmonary embolism, and aortic aneurysm, with hazard ratio (HR) 0.72 (95\% confidence interval (CI) $0.54-0.96$ ) [7]. Three secondary endpoints related to CVD were also tested in the PREDIMED [7]:

1. fatal and non-fatal MI; HR 0.74 (95\% CI 0.46-1.19),

2. fatal and non-fatal stroke;HR 0.54 (95\% CI 0.35-0.84), and

3. CVD mortality, comprising CVD death other than MI and stroke (not affected by the nut intervention; HR 1.01, 95\% CI 0.61-1.66). 
We then obtained data on the total number of first-incident fatal and non-fatal MI and stroke in the population in 2013 (after seven disease-free years), and deaths from the other CVDs, from the Patient Register and Cause of Death Register (National Board of Health and Welfare). To match the PREDIMED study, we focused on the age group 55- to 79-year-old women and men.

Based on the HRs reported in the PREDIMED trial as stated above and the assumption that the population increased nut consumption from on average 5 to $30 \mathrm{~g} /$ day individual consumption, we estimated:

- the number of incident composite CVD, MI, and stroke events that could potentially be prevented ((1-HR) times the number of events in the population) and

- the corresponding reduction in disease burden, expressed as DALYs due to fatal and non-fatal MI and stroke.

We did not include the secondary endpoint CVD deaths (other than MI or stroke) as a separate outcome in the assessment of DALYs. DALYs were calculated as the sum of years lost to disability (YLD) and years of life lost (YLL) as a result of pre-term mortality due to MI and stroke, where

$$
\mathrm{YLL}=\mathrm{N} \times \mathrm{L}
$$

$\mathrm{N}=$ mortality rates, $\mathrm{L}=$ life expectancy at obtained age. And

$$
\mathrm{YLD}=\mathrm{I} \times \mathrm{DW} \times \mathrm{L}
$$

$\mathrm{I}=$ incidence, $\mathrm{DW}=$ disability weight, $\mathrm{L}=$ expected duration of disability. The DW factors used were 0.439 for non-fatal cases of MI and DW $=0.266$ for stroke [21]. The long-term survival time after MI was obtained by assuming that the mortality rate in each age group was twice as high after MI as the average mortality rate in that age group [22]. Corresponding data for stroke cases were obtained from Eriksson et al., who estimated the long-term survival after a first stroke, from which a straight-line extrapolation of survival was made after the end of study follow-up [23].

\subsection{Estimating Risk: Aflatoxin Exposure and Liver Cancer}

To predict the risk, we estimated the average aflatoxin $B_{1}$ exposure via nuts in the study population and compared the exposure to existing risk assessments for liver cancer [10]. We used the mean aflatoxin $B_{1}$ concentrations obtained for the various nut types, sampled within the EU during the period 2000-2006 [8], to estimate aflatoxin $B_{1}$ exposure at the current population average consumption (5 g nuts/day) [15] and in the scenario of $30 \mathrm{~g}$ nuts/day. Although there are several aflatoxin congeners (e.g., $B_{1}, G_{1}, M_{1}, B_{2}, G_{2}$ ), most of the available toxicological data relate to aflatoxin $B_{1}$ and its relative potency is highest $\left(B_{1}>\left(G_{1}, M_{1}\right)>>\left(B_{2}, G_{2}\right)\right)$. Moreover, $B_{1}$ is the most frequent aflatoxin present in contaminated samples, whereas $B_{2}, G_{1}$, and $G_{2}$ are generally not reported in the absence of $B_{1}$ [8]. The levels of aflatoxin $B_{1}$ vary considerably both within and between different types of nuts, as is apparent in terms of both number of samples with detectable levels and actual levels observed. No detectable levels (i.e., concentrations below the limit of detection) are observed in 70-90\% of samples of almonds, hazelnuts, peanuts, cashews, and "other nuts" analyzed in the EU, while the corresponding proportion of non-detectable levels for both pistachios and Brazil nuts is only 56\% [7]. The highest concentrations of aflatoxin $B_{1}$ are also detected in these two nut types [7]. In order not to underestimate the exposure, non-detection of aflatoxin $B_{1}$ concentrations was set at the limit of detection for each nut type $(\approx 0.1-0.2 \mu \mathrm{g} / \mathrm{kg})$ and subsequently used to calculate the mean contamination level in nuts. This resulted in an average of $6.4 \mu \mathrm{g}$ aflatoxin $\mathrm{B}_{1} / \mathrm{kg}$ nuts for all nut types, while excluding pistachios and Brazil nuts resulted in an average of $1.2 \mu \mathrm{g} / \mathrm{kg}$. Therefore, we performed separate intake estimations for the group of all nuts and for nuts excluding pistachios and Brazil nuts.

Based on epidemiological data and a model average from the different statistical models used, the Joint FAO/WHO Expert Committee on Food Additives (JECFA) estimates that aflatoxin $B_{1}$ exposure 
of $1 \mathrm{ng} / \mathrm{kg}$ body weight (bw) and day results in roughly one additional case of liver cancer per 10 million individuals each year in a population of non-carriers of hepatitis B [10]. This impact was considered independent on the background liver cancer rate. We used this reference point to assess the number of liver cancer cases expected to occur due to increased nut consumption. Data on the number of primary and unspecified liver cancer cases occurring in the Swedish population in 2013 were obtained from the Swedish Cancer Register [24].

Because tolerable daily intake (TDI) is not meaningful to derive for genotoxins, an alternative approach, the margin of exposure (MOE), is used as a complement to the reference dose by JECFA [25]. Thus, we complemented the estimates of expected number of liver cancer cases with estimates of MOE.

$\mathrm{MOE}=$ benchmark dose lower limit (BMDL)/average population exposure in $\mathrm{ng} / \mathrm{kg}$ bw

The benchmark dose (BMD) is a modeling of available data from either animal or epidemiological studies and an extrapolation of the exposure level that would cause a certain predefined increase in cancer incidence relative to the baseline incidence. The BMDL refers to the lower limit of the $\mathrm{CI}$, which takes into account the uncertainty inherent in the underlying studies, assuring with $95 \%$ confidence that the chosen adverse response is not exceeded. For aflatoxin $B_{1}$, the European Food Safety Authority (EFSA) has derived BMDL values based both on animal studies and on epidemiological data [8]. From animal data, the $\mathrm{BMDL}_{10}(10 \%$ higher incidence of cancer relative to baseline) is set to $170 \mathrm{ng} / \mathrm{kg}$ bw/day. From human data, the $\mathrm{BMDL}_{10}$ is set to $870 \mathrm{ng} / \mathrm{kg}$ bw $/$ day and $\mathrm{BMDL}_{1}(1 \%$ higher incidence of cancer relative to baseline) to $78 \mathrm{ng} / \mathrm{kg} \mathrm{bw} /$ day [8]. As a rule of thumb, a MOE of 10,000 or more based on data from animal studies indicates exposure of low public health concern.

Because the estimates of both dietary aflatoxin $B_{1}$ exposure and number of liver cancer cases attributable to the exposure were based on several assumptions, detailed assessment of DALYs from liver cancer was not meaningful. Instead, we simplified the DALY estimations by assuming that, irrespective of sex, all liver cancer diagnoses occurred at age 30 years and that all had immediate fatal outcome (DALYs = YLL), with a remaining life expectancy of 53 years [26]. The rationale for using age 30 years was to avoid underestimation of DALYs compared with using the average age at diagnosis. Liver cancer is rare at a young age and the likelihood of a link to lifestyle factors such as nut consumption is lower.

The analyses presented in this paper are scenarios with published data from the PREDIMED trial and publicly available national data. Thus, no data collection was performed and therefore ethical approval and informed consent are not applicable for this study.

\section{Results}

The modeled change in iso-caloric replacement of part of the average diet with $30 \mathrm{~g}$ nuts of the PREDIMED mix resulted in an average 50\% increase in PUFA and 20\% increase in monounsaturated fatty acid (MUFA) intake (Table A1). Intake of vitamin E and magnesium was also increased.

For the primary endpoint, the composite CVD (including fatal and non-fatal MI and stroke, and other CVD deaths), 27,428 cases (1094/100,000 person-years) occurred in 55- to 79-year-olds in Sweden 2013. The $28 \%$ lower risk (95\% CI 4-46\%) obtained for this primary outcome in the group supplemented with $30 \mathrm{~g}$ of nuts / day in PREDIMED would thus result in 7680 prevented cases $(95 \% \mathrm{CI}$ $1097-12,617)$, corresponding to $306 / 100,000$ person-years. The estimated number of preventable cases of MI and stroke, corresponding to the two secondary endpoints, was 3715 (95\% CI 0-7715) and 5390 (95\% CI 1875-7617) respectively (Tables 1 and 2). 
Table 1. Estimated absolute gain in health impact attributable to first incident MI in the Swedish population aged 55-79 years in 2013, by increasing the nut consumption from current average of $5 \mathrm{~g} /$ day to a scenario where everyone consumes $30 \mathrm{~g} /$ day.

\begin{tabular}{|c|c|c|c|c|c|c|c|c|c|c|c|c|}
\hline & \multicolumn{5}{|c|}{ Current Average Intake (5 g/Day) } & \multicolumn{3}{|c|}{ At $30 \mathrm{~g}$ Nuts/Day ${ }^{2}$} & \multicolumn{4}{|c|}{ Gain } \\
\hline & I & No of Cases ${ }^{1}$ & YLL & YLD $^{3}$ & $\overline{\text { DALYs }}$ & YLL & YLD $^{3}$ & $\overline{\text { DALYs }}$ & Prevented Cases & YLL & YLD $^{3}$ & $\overline{\text { DALYs }}$ \\
\hline \multicolumn{13}{|l|}{ Women } \\
\hline $60-64$ & 189 & 549 & 3366 & 166 & 3533 & 2491 & 123 & 2614 & 143 & 875 & 43 & 918 \\
\hline $65-69$ & 293 & 886 & 5256 & 251 & 5507 & 3890 & 186 & 4075 & 230 & 1367 & 65 & 1432 \\
\hline $70-74$ & 504 & 1128 & 7416 & 347 & 7763 & 5488 & 257 & 5745 & 293 & 1928 & 90 & 2018 \\
\hline $55-59$ & 426 & 1232 & 7026 & 410 & 7436 & 5199 & 304 & 5503 & 320 & 1827 & 107 & 1933 \\
\hline $60-64$ & 618 & 1778 & 10,334 & 515 & 10,848 & 7647 & 381 & 8028 & 462 & 2687 & 134 & 2821 \\
\hline $65-69$ & 803 & 2388 & 14,688 & 659 & 15,346 & 10,869 & 487 & 11,356 & 621 & 3819 & 171 & 3990 \\
\hline $70-74$ & 1,126 & 2387 & 13,360 & 631 & 13,991 & 9887 & 467 & 10,353 & 621 & 3474 & 164 & 3638 \\
\hline $75-79$ & 1,510 & 2195 & 10,338 & 541 & 10,879 & 7650 & 400 & 8050 & 571 & 2688 & 141 & 2828 \\
\hline All ages & 810 & 9980 & 55,746 & 2755 & 58,501 & 41,252 & 2039 & 43,291 & 2595 & 14,494 & 716 & 15,210 \\
\hline
\end{tabular}

Abbreviations: MI, myocardial infarction; I, incidence; YLL, years of life lost; YLD, years lost to disability; DALYs, disability-adjusted life years. ${ }^{1}$ Number of MI in $2013 .{ }^{2}$ Based on a reduced risk of HR 0.74 by increased consumption of walnuts, hazelnuts, and almonds [6] in a scenario where everyone in the population consumes $30 \mathrm{~g} /$ day. ${ }^{3}$ Disability weight 0.439 [18]. 
Table 2. Estimated absolute gain in health impact attributable to first incident stroke in the Swedish population aged 55-79 years in 2013 , by increasing the nut consumption from current average of $5 \mathrm{~g} /$ day to a scenario where everyone consumes $30 \mathrm{~g} /$ day.

\begin{tabular}{|c|c|c|c|c|c|c|c|c|c|c|c|c|}
\hline & \multicolumn{5}{|c|}{ Current Average Intake (5 g/Day) } & \multicolumn{3}{|c|}{ At 30 g Nuts/Day ${ }^{2}$} & \multicolumn{4}{|c|}{ Gain } \\
\hline & I & No of Cases ${ }^{1}$ & YLL & YLD $^{3}$ & DALYs & YLL & YLD $^{3}$ & DALYs & Prevented Cases & YLL & YLD $^{3}$ & $\overline{\text { DALYs }}$ \\
\hline \multicolumn{13}{|l|}{ Women } \\
\hline $60-64$ & 194 & 561 & 7288 & 1326 & 8614 & 3935 & 716 & 4652 & 258 & 3352 & 610 & 3962 \\
\hline $65-69$ & 320 & 968 & 9025 & 2227 & 11,252 & 4874 & 1203 & 6076 & 445 & 4152 & 1024 & 5176 \\
\hline $70-74$ & 542 & 1211 & 9531 & 2162 & 11,693 & 5147 & 1168 & 6314 & 557 & 4384 & 995 & 5379 \\
\hline $75-79$ & 906 & 1554 & 9453 & 1990 & 11,444 & 5105 & 1075 & 6180 & 715 & 4348 & 916 & 5264 \\
\hline $55-59$ & 225 & 651 & 11,008 & 1228 & 12,236 & 5944 & 663 & 6607 & 299 & 5064 & 565 & 5629 \\
\hline $60-64$ & 378 & 1089 & 13,519 & 2053 & 15,572 & 7300 & 1108 & 8409 & 501 & 6219 & 944 & 7163 \\
\hline $65-69$ & 545 & 1619 & 12,590 & 3393 & 15,983 & 6799 & 1832 & 8631 & 745 & 5791 & 1561 & 7352 \\
\hline $70-74$ & 864 & 1832 & 11,763 & 2972 & 14,736 & 6352 & 1605 & 7957 & 843 & 5411 & 1367 & 6778 \\
\hline $75-79$ & 1291 & 1887 & 9140 & 2202 & 11,342 & 4935 & 1189 & 6125 & 868 & 4204 & 1013 & 5217 \\
\hline All ages & 1291 & 7078 & 58,020 & 11,849 & 69,869 & 31,331 & 6398 & 37,729 & 3256 & 26,689 & 5450 & 32,140 \\
\hline
\end{tabular}

Abbreviations: I, incidence; YLL, years of life lost; YLD, years lost to disability; DALYs, disability-adjusted life years. ${ }^{1}$ Number of stroke cases in $2013 .{ }^{2}$ Based on a reduced risk of HR 0.54 by increased consumption of walnuts, hazelnuts, and almonds [6] in a scenario where everyone in the population consumes $30 \mathrm{~g} /$ day. ${ }^{3}$ Disability weight 0.266 [18]. 
The absolute health impact, expressed as DALYs gained by increasing current nut consumption to $30 \mathrm{~g} /$ day, was about 22,000 for MI (Table 1) and 55,000 for stroke (Table 2) in women and men combined. Most of the DALYs were attributed to mortality, especially for MI, where time lived with disability was expected to be short. The higher incidence of MI and stroke among men than among women was reflected in higher DALYs for men.

As shown in Table 3, in the scenario where Brazil nuts and pistachios were excluded from consumption, the estimated exposure to aflatoxin $B_{1}$ from nuts $(0.4-0.5 \mathrm{ng} / \mathrm{kg}$ bw and day) did not reach the exposure level of $1 \mathrm{ng} / \mathrm{kg}$ bw and day, resulting in no additional cases of liver cancer in the population (Table 3). The corresponding calculation based on a nut mixture that included Brazil nuts and pistachios resulted in aflatoxin $B_{1}$ exposure of $2.3-2.8 \mathrm{ng} / \mathrm{kg}$ bw and day, which may correspond to three additional cases of liver cancer each year in Sweden. On the other hand, the estimated MOE, 60-400 based on animal data, indicated a public health concern in both exposure scenarios, since the margin of 10,000 was not met. The scenario of three additional cases of liver cancer at age of 30 years, no disability, and with a fatal outcome resulted in an estimated 159 DALYs from liver cancer associated with nut consumption.

Table 3. Aflatoxin $\mathrm{B}_{1}$ exposure and margin of exposure (MOE) by sex and level of nut consumption.

\begin{tabular}{|c|c|c|c|c|}
\hline \multirow[b]{2}{*}{ Nut consumption (g/day) } & \multicolumn{2}{|c|}{ All Nuts ${ }^{1}$} & \multicolumn{2}{|c|}{ All Nuts Excluding Brazil Nuts and Pistachios ${ }^{2}$} \\
\hline & 5 & 30 & 5 & 30 \\
\hline \multicolumn{5}{|l|}{ Women, $69 \mathrm{~kg}$} \\
\hline Aflatoxin $B_{1}$ exposure, $\mathrm{ng} / \mathrm{kg}$ bw day & 0.5 & 2.8 & 0.08 & 0.5 \\
\hline MOE, animal data ${ }^{3}$ & 370 & 60 & 2100 & 350 \\
\hline MOE, human data ${ }^{4}$ & 1900 & 310 & 10,700 & 1800 \\
\hline \multicolumn{5}{|l|}{ Men, $84 \mathrm{~kg}$} \\
\hline Aflatoxin $\mathrm{B}_{1}$ exposure, $\mathrm{ng} / \mathrm{kg}$ bw day & 0.4 & 2.3 & 0.07 & 0.4 \\
\hline MOE, animal data ${ }^{3}$ & 445 & 75 & 2400 & 402 \\
\hline MOE, human data 4 & 2300 & 380 & 12,300 & 2200 \\
\hline
\end{tabular}

${ }^{1}$ Mean aflatoxin $B_{1}$ concentration of $6.4 \mu \mathrm{g} / \mathrm{kg}$ nut for cashews, hazelnuts, peanuts, almonds, pistachios, Brazil nuts, and "other nuts" sampled in the EU 2000-2006 [8]. ${ }^{2}$ Mean aflatoxin B $B_{1}$ concentration of $1.2 \mu \mathrm{g} / \mathrm{kg}$ nut for cashews, hazelnuts, peanuts, almonds, and "other nuts" sampled in the EU 2000-2006 [8]. ${ }^{3}$ Based on benchmark dose lower limit (BMDL) 10 of $170 \mathrm{ng} / \mathrm{kg}$ bw day from animal data. ${ }^{4}$ Based on BMDL 10 of $870 \mathrm{ng} / \mathrm{kg}$ bw day from human data.

\section{Discussion}

In the population of Swedish residents aged 55-79 years in 2013, with an average low exposure to aflatoxins, increasing the nut consumption from the current average of five grams per day to individual consumption of $30 \mathrm{~g}$ /day could prevent 7680 individuals from developing a first CVD (306/100,000 person-year) and could contribute about 55,000 saved DALYs for stroke and 22,000 for MI. At the same time, the potential increase in aflatoxin $B_{1}$ exposure would lead to an estimated zero to three additional cases of liver cancer in the population, corresponding to approximately 159 DALYs. Thus, the population health benefits provided by increased nut consumption clearly outweigh the risks associated with increased aflatoxin $\mathrm{B}_{1}$ exposure.

The combined epidemiological evidence [1,2,4] and results from RCTs [6,7] provide unusually strong support for positive health effects of nuts, with the group "nuts and seeds" being graded high on most criteria for causality in prevention of ischemic heart disease [4]. This despite the fact that observational data indicate that nut eaters generally have a healthier lifestyle than people who never or rarely consume nuts $[27,28]$. Moreover, the association between nut consumption and CVD health is evident in a range of populations, despite imprecise assessments of dose and types [2].

The use of RCT data was supported by a similar incidence of ischemic heart disease in the studied Swedish residents as in the trial population, despite the fact that the PREDIMED subjects were chosen to be at higher risk of CVD. In any case, the risk estimates were similar in the RCT and in the summary of observational studies: for CVD the relative risk (RR) was 0.79 (95\% CI 0.70-0.88)/28 g/day serving [1], compared with HR 0.72 for composite CVD in the group consuming $30 \mathrm{~g}$ nuts/day in the PREDIMED 
RCT [7]. In contrast to the RCT, recent meta-analyses do not show any significant associations between nut intake and risk of stroke, either as total (RR 0.93; 95\% CI 0.83-1.05) [1], ischemic (RR 1.06; 95\% CI 0.81-1.38) [2], or stroke mortality (RR $0.83 ; 95 \%$ CI 0.69-1.00) [2]. Indications of an inverse association with stroke incidence up to an intake of 15-20 g nuts/day (non-linear association) [1] and with intake of peanuts [1,29] and walnuts [29] have been observed, but a recent evaluation graded the evidence for stroke as very low [2]. A potential counteracting effect of salt, often added to nuts (but not in the PREDIMED trial), on stroke risk cannot be excluded.

The favorable fat composition of nuts and the content of micronutrients, bioactive compounds, and dietary fiber may contribute to lower CVD by improving the cardio-metabolic profile [6]. Increased nut consumption is one way to increase adherence to the dietary recommendations on fat intake, where roughly two-thirds should comprise unsaturated fats [30,31]. A 30 g portion of nuts (about a handful, corresponding to $10 \%$ of total energy intake), compared with the low current average Swedish nut consumption, can be considered a major dietary change. However, a recent meta-analysis indicated that smaller amounts are also associated with health benefits [1]. Dose-response data indicate lower risk for coronary heart disease with increasing nut consumption up to about 10-15 g/day [3] and association with reductions in all-cause mortality up to 15-20 g/day [5]. Micha et al. concluded that five servings/week, each of about $28 \mathrm{~g}$, is the optimal mean population intake based on ischemic heart disease prevention [4].

A MOE of 10,000 or higher, based on $\mathrm{BMDL}_{10}$ from an animal study, is suggested to be a low public health concern [25], but was not met even at the current level of nut consumption. At present, there is no alternative margin proposed for data based on epidemiological studies in humans. The MOEs obtained from animal data after increased consumption are substantially lower (60-400) than the desirable margin, however, well agreeing with our estimate of zero to three additional cases of liver cancer in the total population. Focusing on aflatoxin $B_{1}$ exposure alone, increased nut consumption is clearly of public health concern, while broadening the picture to include beneficial effects of nuts on CVDs indicates that many more lives are saved than lost.

We focused on CVD and liver cancer alone, although nut consumption has been associated with reduced all-cause mortality $[1,2,5]$ and type 2 diabetes $[4,32]$ and improved weight maintenance [33,34], but also with exposure to salmonella [35] and acrylamide [35]. Prevention of premature deaths would have a large impact on the population, but we chose not to include this imprecise outcome in our assessment. The effect on weight maintenance and type 2 diabetes could be of public health importance, but data on effect size are not as certain as for CVD. Risk of salmonellosis was judged to be limited, as was the risk associated with acrylamide exposure from heat-treated nuts [35]. Allergy to peanuts and tree nuts, which is common in Sweden, is another potential health concern. People who are allergic to nuts may have greater difficulties avoiding nuts if overall consumption increases, an effect we did not account for in our scenario. On the other hand, measures to prevent allergy are currently under discussion and avoidance of highly allergenic foods such as peanuts is no longer the preferred strategy for allergy prevention [36].

The present study is one of only a few to weigh health benefits against risks of foods using the burden of disease as an outcome and is unique in doing so for nuts, which has implications for dietary guidelines worldwide. One strength of our study is the fact that the assessment of CVD benefits was based on risk estimates from an RCT, providing the highest grade of evidence and lowering the risk of bias due to, e.g., confounding effects. The availability of reliable data on morbidity and mortality in the Swedish population $[37,38]$ was also a strength.

There are important limitations of our study. First, and most importantly, our results are conditional on consumption of nuts and their impact on CVD incidence in our study population resembling those in the PREDIMED study. Obviously, the effect of increased nut consumption in our studied population, with a dietary pattern different from the Mediterranean diet, is unknown. Thus, the estimated number of prevented cases needs to be considered tentative in a public health context of CVD prevention, although still justified and valid for the purpose of our risk-benefit 
comparison. Importantly, our results were robust in the sense that the conclusion prevails even if the part of CVD reduction attributed to nuts would be considerably lower. The results are also conditional on the assumption that there was no net increase in energy intake altering any risk factor profile in the population and that aflatoxin $B_{1}$ concentration in nuts sampled within the $\mathrm{EU}$ is representative of the exposure in the target population. The varying aflatoxin $B_{1}$ concentrations present in nuts clearly introduce uncertainties, and we did not assess any adverse effect of exceeding the target consumption of $30 \mathrm{~g} /$ day.

Second, for comparing different disease outcomes we used DALYs despite the uncertainty that follows with making the necessary assumptions. DALYs is the most accepted measure for comparing disease and risk factors and used in the Global Burden of Disease project [39]. Because register information was not cross-linked in the present study, we could not exclude the possibility that some individuals with incident non-fatal MI or stroke were counted more than once, if they either died from CVD other than MI or stroke in the same year (2013) or encountered both MI and stroke in that year. This may have slightly overestimated the number of prevented cases of composite CVDs. Similarly, we could not exclude the possibility that individuals who suffered from both incident non-fatal MI and stroke during 2013 were counted twice in the estimation of DALYs. However, considering the relatively short period of disability for MI, the subsequent overestimation of DALYs is likely minor. Furthermore, data on proportions with specific disabilities among the stroke cases in our population were not available, preventing us from sub-classifying stroke cases according to the most recent DWs [40], and thus we used composite DWs from 2004 [21]. This could have influenced our estimated DALYs in any direction.

Third, the lack of data on the potential health impact of aflatoxin exposure in a low-exposure population with a low prevalence of hepatitis [41,42] introduces large uncertainties in estimation of adverse health impacts. Important risk factors for liver cancer are alcohol consumption and chronic hepatitis B infection [8], while aflatoxin is considered unlikely to be a major contributor to liver cancer in the Nordic countries. The JECFA potency estimate is derived from human studies limited to populations with a high prevalence of hepatitis B infection and with very limited information on aflatoxin $B_{1}$ exposure. However, even an unrealistic assumption that all liver cancer in Sweden was due to aflatoxin $B_{1}$ exposure would not change the conclusion that the CVD reductions outweigh the burden of liver cancer.

Altogether, our study provides an example of how different health aspects of a type of food can be included in the same evaluation. Comparing the most pertinent health benefits and potential risks associated with nut consumption, provides strong support for increasing overall nut consumption and for the inclusion of nuts in dietary guidelines. In policymaking, considerations including the environmental impact of nut production, population dietary habits, disease pattern, and allergy prevalence may be necessary.

Future research should focus on the amount and type of nuts for optimal benefits and more resources should be allocated to monitoring the exposure and health impact of aflatoxins in food. Because the intake of aflatoxins from single nuts with high concentrations of aflatoxins is potentially more influential for exposure than the total amount of nuts consumed, the most important measure to limit exposure is to prevent nuts with high aflatoxin concentration from reaching consumers. Improvements in production, storage, and control are vital to ensure that nuts are part of a safe, nutritious diet.

\section{Conclusions}

In a scenario with national data on exposure and outcome, combined with estimates from a RCT, we showed that health benefits, measured as cases of CVD potentially averted and DALYs saved, outweighed any additional cases of liver cancer due to increased nut consumption. Our conclusion is that increased nut consumption, as part of a varied healthy diet, is warranted even when aflatoxin $B_{1}$ exposure is taken into account. However, efforts to reduce aflatoxin exposure from nuts are essential. 
Acknowledgments: This study was supported by National Food Agency, Karolinska Institutet and Umeå University, Sweden. No external funding was received. We wish to express our gratitude to Irene Mattisson and Salomon Sand, National Food Agency, and Anna Bergström, Institute of Environmental Medicine, Karolinska Institutet, Sweden for valuable contribution.

Author Contributions: H.E., S.W. and A.Å. conceived and designed the study; H.E., S.W., K.L., J.N.S. and A.A. analyzed the data; H.E. wrote the paper with substantial contribution from all authors.

Conflicts of Interest: The authors declare no conflict of interest.

\section{Appendix A}

Table A1. Changes in daily nutrient intakes in a scenario where the energy content of the PREDIMED nut mix $817 \mathrm{~kJ}$ replaces the corresponding amount of the average diet in men and women from a nation-wide dietary survey [15].

\begin{tabular}{ccccc}
\hline & \multicolumn{2}{c}{ Women (1005) } & \multicolumn{2}{c}{ Men (792) } \\
\hline & Current Intake & Change, \% & Current Intake & Change, \% \\
\hline Energy, kJ & 7421 & 0 & 9359 & 0 \\
SFA, g & 27 & -5 & 33 & -4 \\
MUFA, g & 26 & 21 & 33 & 17 \\
PUFA, g & 12 & 52 & 14 & 43 \\
Vitamin E, mg & 10 & 26 & 11 & 25 \\
Folate, $\mu \mathrm{g}$ & 253 & -3 & 266 & -1 \\
Calcium, mg & 820 & -5 & 944 & -4 \\
Magnesium, mg & 305 & 17 & 364 & 15 \\
Selenium, $\mu \mathrm{g}$ & 42 & -9 & 50 & -7 \\
Zinc, mg & 10 & -2 & 12 & -2 \\
\hline
\end{tabular}

Abbreviations: SFA, saturated fatty acids; MUFA, monounsaturated fatty acids; PUFA, polyunsaturated fatty acids. Nutrient content from National Food Agency Food Database [43].

\section{References}

1. Aune, D.; Keum, N.; Giovannucci, E.; Fadnes, L.T.; Boffetta, P.; Greenwood, D.C.; Tonstad, S.; Vatten, L.J.; Riboli, E.; Norat, T. Nut consumption and risk of cardiovascular disease, total cancer, all-cause and cause-specific mortality: A systematic review and dose-response meta-analysis of prospective studies. BMC Med. 2016, 14, 207. [CrossRef] [PubMed]

2. Mayhew, A.J.; de Souza, R.J.; Meyre, D.; Anand, S.S.; Mente, A. A systematic review and meta-analysis of nut consumption and incident risk of CVD and all-cause mortality. Br. J. Nutr. 2016, 115, 212-225. [CrossRef] [PubMed]

3. Bechthold, A.; Boeing, H.; Schwedhelm, C.; Hoffmann, G.; Knuppel, S.; Iqbal, K.; De Henauw, S.; Michels, N.; Devleesschauwer, B.; Schlesinger, S.; et al. Food groups and risk of coronary heart disease, stroke and heart failure: A systematic review and dose-response meta-analysis of prospective studies. Crit. Rev. Food Sci. Nutr. 2017, 1-20. [CrossRef] [PubMed]

4. Micha, R.; Shulkin, M.L.; Penalvo, J.L.; Khatibzadeh, S.; Singh, G.M.; Rao, M.; Fahimi, S.; Powles, J.; Mozaffarian, D. Etiologic effects and optimal intakes of foods and nutrients for risk of cardiovascular diseases and diabetes: Systematic reviews and meta-analyses from the nutrition and chronic diseases expert group (nutricode). PLoS ONE 2017, 12, e0175149. [CrossRef] [PubMed]

5. Schwingshackl, L.; Schwedhelm, C.; Hoffmann, G.; Lampousi, A.M.; Knuppel, S.; Iqbal, K.; Bechthold, A.; Schlesinger, S.; Boeing, H. Food groups and risk of all-cause mortality: A systematic review and meta-analysis of prospective studies. Am. J. Clin. Nutr. 2017, 105, 1462-1473. [CrossRef] [PubMed]

6. Del Gobbo, L.C.; Falk, M.C.; Feldman, R.; Lewis, K.; Mozaffarian, D. Effects of tree nuts on blood lipids, apolipoproteins, and blood pressure: Systematic review, meta-analysis, and dose-response of 61 controlled intervention trials. Am. J. Clin. Nutr. 2015, 102, 1347-1356. [CrossRef] [PubMed]

7. Estruch, R.; Ros, E.; Salas-Salvado, J.; Covas, M.I.; Corella, D.; Aros, F.; Gomez-Gracia, E.; Ruiz-Gutierrez, V.; Fiol, M.; Lapetra, J.; et al. Primary prevention of cardiovascular disease with a Mediterranean diet. N. Engl. J. Med. 2013, 368, 1279-1290. [CrossRef] [PubMed] 
8. EFSA. Opinion of the scientific panel on contaminants in the food chain on a request from the commission related to the potential increase of consumer health risk by a possible increase of the existing maximum levels for aflatoxins in almonds, hazelnuts and pistachios and derived products. EFSA J. 2007, 446, 1-127.

9. EFSA. Statement of the scientific panel on contaminants in the food chain on a request from the European Commission on the effects on public health of an increase of the levels for aflatoxin total from $4 \mu \mathrm{g} / \mathrm{kg}$ to $10 \mu \mathrm{g} / \mathrm{kg}$ for tree nuts other than almonds, hazelnuts and pistachios. EFSA J. 2009, 1168, 1-11.

10. World Health Organization, Joint FAO/WHO Expert Committee on Food Additives. Evaluation of Certain Contaminants in Food: Eighty-Third Report of the Joint FAO/WHO Expert Committee on Food Additives; World Health Organization: Geneva, Switzerland, 2017; pp. 11-40.

11. Ferlay, J.; Soerjomataram, I.; Dikshit, R.; Eser, S.; Mathers, C.; Rebelo, M.; Parkin, D.M.; Forman, D.; Bray, F. Cancer incidence and mortality worldwide: Sources, methods and major patterns in GLOBOCAN 2012. Int. J. Cancer 2015, 136, E359-E386. [CrossRef] [PubMed]

12. Liu, Y.; Chang, C.C.; Marsh, G.M.; Wu, F. Population attributable risk of aflatoxin-related liver cancer: Systematic review and meta-analysis. Eur. J. Cancer 2012, 48, 2125-2136. [CrossRef] [PubMed]

13. Joint FAO/WHO Expert Committee on Food Additives. In Summary and Conclusions from the Eighty-Third Meeting. Available online: http:/ / www.fao.org/3/a-bq821e.pdf (accessed on 30 October 2017).

14. Boobis, A.; Chiodini, A.; Hoekstra, J.; Lagiou, P.; Przyrembel, H.; Schlatter, J.; Schutte, K.; Verhagen, H.; Watzl, B. Critical appraisal of the assessment of benefits and risks for foods, 'BRAFO consensus working group'. Food Chem. Toxicol. 2013, 55, 659-675. [CrossRef] [PubMed]

15. Riksmaten -Vuxna 2010-11 Ivsmedels- och Näringsintag Bland Vuxna i Sverige (Dietary Habits and Nutrient Intake in Sweden 2010-11). Available online: https:/ / www.livsmedelsverket.se/globalassets / matvanor-halsa-miljo/kostrad-matvanor/matvaneundersokningar/riksmaten_2010_20111.pdf (accessed on 30 October 2017).

16. Wilkins, E.; Wilson, L.; Wickramasinghe, K.; Bhatnagar, P.; Leal, J.; Luengo-Fernandez, R.; Burns, R.; Rayner, M.; Townsend, N. European Cardiovascular Disease Statistics 2017; European Heart Network: Brussels, Belgium, 2017.

17. Statistics Sweden. Statistikdatabasen (Population by Region, Age and Sex 2006-2016). Available online: http:/ / www.Statistikdatabasen.Scb.Se/pxweb/sv/ssd/start_be_be0101_be0101d/medelfolkfodelsear/ ?Rxid=914a6b1b-2534-4663-8681-bf4302f146fb (accessed on 18 August 2017).

18. Townsend, N.; Wilson, L.; Bhatnagar, P.; Wickramasinghe, K.; Rayner, M.; Nichols, M. Cardiovascular disease in Europe: Epidemiological update 2016. Eur. Heart J. 2016, 37, 3232-3245. [CrossRef] [PubMed]

19. Roth, G.A.; Johnson, C.; Abajobir, A.; Abd-Allah, F.; Abera, S.F.; Abyu, G.; Ahmed, M.; Aksut, B.; Alam, T.; Alam, K.; et al. Global, regional, and national burden of cardiovascular diseases for 10 causes, 1990 to 2015. J. Am. Coll. Cardiol. 2017. [CrossRef] [PubMed]

20. National Board of Health and Welfare and the Swedish Cancer Society. Cancer i Siffror 2013 (Cancer in Numbers 2013). Available online: http:/ / www.socialstyrelsen.se/publikationer2013/2013-6-5 (accessed on 30 October 2017).

21. Global Burden of Disease 2004 Update: Disability Weights for Diseases and Conditions. Available online: http:/ / www.who.int/healthinfo/global_burden_disease/GBD2004_DisabilityWeights.pdf (accessed on 30 October 2017).

22. Smolina, K.; Wright, F.L.; Rayner, M.; Goldacre, M.J. Long-term survival and recurrence after acute myocardial infarction in England, 2004 to 2010. Circ. Cardiovasc. Qual. Outcomes 2012, 5, 532-540. [CrossRef] [PubMed]

23. Eriksson, M.; Carlberg, B.; Eliasson, M. The disparity in long-term survival after a first stroke in patients with and without diabetes persists: The Northern Sweden Monica study. Cerebrovasc. Dis. 2012, 34, 153-160. [CrossRef] [PubMed]

24. National Board of Health and Welfare. Statistikdatabasen (National Population Statistics). Available online: http:/ / www.Socialstyrelsen.Se/statistik/statistikdatabas/ (accessed on 18 August 2017).

25. EFSA. Opinion of the scientific committee on a request from EFSA related to a harmonised approach for risk assessment of substances which are both genotoxic and carcinogenic. EFSA J. 2005, 282, 1-31.

26. Life Expectancy in Sweden 2011-2015. Available online: https://www.scb.se/Statistik/_Publikationer/ BE0701_2016A01R_BR_BE51BR1604.pdf (accessed on 30 October 2017). 
27. Bao, Y.; Han, J.; Hu, F.B.; Giovannucci, E.L.; Stampfer, M.J.; Willett, W.C.; Fuchs, C.S. Association of nut consumption with total and cause-specific mortality. N. Engl. J. Med. 2013, 369, 2001-2011. [CrossRef] [PubMed]

28. Brown, R.C.; Tey, S.L.; Gray, A.R.; Chisholm, A.; Smith, C.; Fleming, E.; Parnell, W. Nut consumption is associated with better nutrient intakes: Results from the 2008/09 New Zealand adult nutrition survey. Br. J. Nutr. 2016, 115, 105-112. [CrossRef] [PubMed]

29. Guasch-Ferré, M.; Liu, X.; Malik, V.S.; Sun, Q.; Willett, W.C.; Manson, J.E.; Rexrode, K.M.; Li, Y.; Hu, F.B.; Bhupathiraju, S.N. Nut consumption and risk of cardiovascular disease. J. Am. Coll. Cardiol. 2017, 70, 2519-2532. [CrossRef] [PubMed]

30. Nordic Nutrition Recommendations 2012: Integrating Nutrition and Physical Activity. Available online: http:/ / www.norden.org/en/theme/former-themes/themes-2016/nordic-nutrition-recommendation/ nordic-nutrition-recommendations-2012 (accessed on 30 October 2017).

31. Fats and Fatty Acids in Human Nutrition. Available online: http://www.fao.org/3/a-i1953e.pdf (accessed on 30 October 2017).

32. Schwingshackl, L.; Hoffmann, G.; Lampousi, A.M.; Knuppel, S.; Iqbal, K.; Schwedhelm, C.; Bechthold, A.; Schlesinger, S.; Boeing, H. Food groups and risk of type 2 diabetes mellitus: A systematic review and meta-analysis of prospective studies. Eur. J. Epidemiol. 2017, 32, 363-375. [CrossRef] [PubMed]

33. Fogelholm, M.; Anderssen, S.; Gunnarsdottir, I.; Lahti-Koski, M. Dietary macronutrients and food consumption as determinants of long-term weight change in adult populations: A systematic literature review. Food Nutr. Res. 2012, 56. [CrossRef] [PubMed]

34. Flores-Mateo, G.; Rojas-Rueda, D.; Basora, J.; Ros, E.; Salas-Salvado, J. Nut intake and adiposity: Meta-analysis of clinical trials. Am. J. Clin. Nutr. 2013, 97, 1346-1355. [CrossRef] [PubMed]

35. National Food Agency. Risk- och Nyttovärdering av Nötter -Sammanställning av Hälsoeffekter av Nötkonsumtion (Risk- and Benefit Assessment of Nuts-A Summary of Health Effects of nut Consumption). Report 16:2014. National Food Agency: Uppsala, Sweden, 2014. Available online: https:/ / www.livsmedelsverket.se/globalassets / rapporter/2014/2014_livsmedelsverket_16_risk_ nyttovardering_notter.pdf (accessed on 30 October 2017).

36. Turner, P.; Campbell, D. Implementing primary prevention for peanut allergy at a population level. JAMA 2017, 317, 1111-1112. [CrossRef] [PubMed]

37. Ludvigsson, J.F.; Almqvist, C.; Bonamy, A.-K.E.; Ljung, R.; Michaëlsson, K.; Neovius, M.; Stephansson, O.; Ye, W. Registers of the Swedish total population and their use in medical research. Eur. J. Epidemiol. 2016, 31, 125-136. [CrossRef] [PubMed]

38. Ludvigsson, J.F.; Andersson, E.; Ekbom, A.; Feychting, M.; Kim, J.L.; Reuterwall, C.; Heurgren, M.; Olausson, P.O. External review and validation of the Swedish national inpatient register. BMC Public Health 2011, 11, 450. [CrossRef] [PubMed]

39. GBD 2016 DALYs and HALE Collaborators. Global, regional, and national disability-adjusted life-years (DALYs) for 333 diseases and injuries and healthy life expectancy (HALE) for 195 countries and territories, 1990-2016: A systematic analysis for the global burden of disease study 2016. Lancet 2017, 390, 1260-1344.

40. Salomon, J.A.; Haagsma, J.A.; Davis, A.; de Noordhout, C.M.; Polinder, S.; Havelaar, A.H.; Cassini, A.; Devleesschauwer, B.; Kretzschmar, M.; Speybroeck, N.; et al. Disability weights for the global burden of disease 2013 study. Lancet Glob. Health 2015, 3, e712-e723. [CrossRef]

41. Busch, K.; Kovamees, J.; Söderholm, J. Prevalence of hepatitis C and presence of comorbidities in Sweden: A nationwide population-based register study. Value Health 2015, 18, A575-A576. [CrossRef] [PubMed]

42. Struve, J.; Giesecke, J.; Olcen, P.; von Sydow, M.; Weiland, O. Prevalence of hepatitis B virus markers in Sweden: A community-based serosurvey of 4000 young Swedish adults. Am. J. Epidemiol. 1992, 135, 409-417. [CrossRef] [PubMed]

43. National Food Agency. Livsmedelsdatabasen. Food Database Search for Nutrients. Available online: http:/ / www7.Slv.Se/soknaringsinnehall/ (accessed on 15 September 2017).

(C) 2017 by the authors. Licensee MDPI, Basel, Switzerland. This article is an open access article distributed under the terms and conditions of the Creative Commons Attribution (CC BY) license (http:/ / creativecommons.org/licenses/by/4.0/). 